\title{
Sobre o gênero Vesicapalpus (Araneae, Linyphiidae) no sul do Brasil
}

\author{
Everton Nei Lopes Rodrigues \& Ricardo Ott
}

Museu de Ciências Naturais, Fundação Zoobotânica do Rio Grande do Sul, Rua Dr. Salvador França, 1427, 90690-000 Porto Alegre, RS, Brasil. (enlrodrigues@yahoo.com.br; rott@fzb.rs.gov.br)

\begin{abstract}
On the genus Vesicapalpus (Araneae, Linyphiidae) in southern Brazil. Vesicapalpus serranus sp. nov., from the State of Rio Grande do Sul, is described, illustrated and ecological data on this species are presented. The female of Vesicapalpus simplex Millidge, 1991 is described, illustrated and new geographical distribution data are provided.
\end{abstract}

KEYWORDS. Vesicapalpus, Neotropical, taxonomy, ecology, phenology.

RESUMO. Vesicapalpus serranus sp. nov., do Estado do Rio Grande do Sul, é descrita, ilustrada e são apresentados dados ecológicos desta espécie. A fêmea de Vesicapalpus simplex Millidge, 1991 é descrita, ilustrada e novos dados de distribuição geográfica são fornecidos.

PALAVRAS-CHAVE. Vesicapalpus, Neotropical, taxonomia, ecologia, fenologia.

O gênero Vesicapalpus foi proposto por MiLlidge (1991) incluindo somente a espécie-tipo V. simplex Millidge, 1991, descrita para Misiones, Argentina e representada por um indivíduo macho. O gênero é caracterizado pelo palpo do macho com o tégulo dilatado, divisão embólica relativamente simples e apófise suprategular curvada e pontiaguda (Millidge, 1991). Recentemente, Hormiga (1999) estudou os sulcos encontrados no cefalotórax (pits) de aranhas da subfamília Linyphiinae, documentando pela primeira vez esta estrutura em $V$. simplex, e descreveu como nãohomólogos os sulcos encontrados em Vesicapalpus com o das demais espécies estudadas da subfamília.

Neste trabalho é descrita uma nova espécie de Vesicapalpus e são apresentados dados ecológicos a partir de indivíduos coletados com armadilhas de solo ("pitfall-traps") no CPCN Pró-Mata, São Francisco de Paula, RS, Brasil. Também é descrita a fêmea de $V$. simplex Millidge, 1991 e são registradas novas ocorrências da espécie.

\section{MATERIAL E MÉTODOS}

A coleta dos exemplares de Vesicapalpus serranus sp. nov. foi realizada no Centro de Pesquisas e Conservação da Natureza (CPCN) Pró-Mata, São Francisco de Paula, RS. Seis áreas de floresta foram escolhidas para as amostragens: duas de Floresta Ombrófila Mista, bem conservadas (ARA), duas de floresta secundária (SEC) e duas de silvicultura de Pinus spp. (PIN). Em cada área, foram escolhidos dois transectos e, sobre cada um, instaladas cinco armadilhas de queda, uma a cada 10 metros, num total de dez armadilhas para cada uma das áreas. As amostragens foram realizadas, ininterruptamente, ao longo de 20 meses de coleta, totalizando 18 datas amostrais (Fig. 8).

Para comparação do número de indivíduos registrados em cada sexo, foi utilizado o teste "t pareado" (ZAR, 1999); os dados foram agrupados considerando-se a soma total de indivíduos de cada sexo em cada uma das 60 armadilhas ( 10 de cada em cada área) ao longo de todo período amostral (60 pares). Para a comparação das médias de indivíduos, obtidas entre os três diferentes tipos de hábitats (ARA, SEC e PIN), foi aplicado teste de hipóteses através da Análise de Variância (ANOVA; ZAR, 1999), tendo sido consideradas as médias dos totais registrados entre as dez armadilhas de cada área; obtiveram-se, desta maneira, duas réplicas para cada tipo de hábitat estudado. Os cálculos foram realizados com o auxílio do programa SigmaStat (JANDEL, 1995); todos consideraram $\alpha=0,05$.

Os espécimes examinados estão depositados nas coleções aracnológicas do Museu de Ciências Naturais, Fundação Zoobotânica do Rio Grande do Sul (MCN, E. H. Buckup) e do Museu de Ciências e Tecnologia da Pontifícia Universidade Católica do Rio Grande do Sul (MCTP, A. A. Lise), Porto Alegre, RS, Brasil. Para o cálculo da posição do tricobótrio no metatarso da perna I (TmI), adotou-se MiLlidge (1980); descrições seguem MiLLIDGE (1985, 1991). O estudo das estruturas internas da genitália da fêmea foi realizado submergindo o epígino em ácido lático por aproximadamente 30 minutos. Medidas são apresentadas em milímetros $(\mathrm{mm})$ e a variação em $V$. serranus $\mathrm{sp}$. nov. está baseada em 10 machos e 10 fêmeas.

\section{Vesicapalpus serranus sp. nov. (Figs. 1-9)}

Material-tipo. Holótipo ơ, BRASIL, Rio Grande do Sul: São Francisco de Paula (CPCN Pró-Mata), 23.XI.2000, R. Ott col., coletado com armadilha de solo (pitfall-trap) (MCN 40054). Parátipos: 10 ơ, 11 \&, mesma localidade do holótipo, 25.X.2000 - 07.VIII.2001, R. Ott col., todos coletados com pitfall-trap (MCN 39418, 39419, 40055, 40056; MCTP 18080, 18113).

Etimologia. O epíteto refere-se à região serrana, onde está localizado o município no qual a espécie foi coletada.

Diagnose. O palpo do macho de Vesicapalpus 
serranus sp. nov. é semelhante ao de V. simplex Millidge, 1991 (Millidge, 1991, figs. 182, 183); difere do mesmo pela divisão embólica com região proximal mais estreita e porção distal afilada; êmbolo não tão longo e afilado, com percurso direcionado para o ápice da divisão embólica, porção proximal com base mais larga; tíbia mais curta e com uma pequena intumescência ventral (Fig. 5). Epígino com átrio de grande abertura arredondada e profunda, dividida por septo mediano longitudinal de base alongada e projetada, inserida na placa dorsal (Fig. 6); espermatecas laterais na porção posterior do átrio (Fig. 7).

Descrição. Holótipo đ. Comprimento total 2,50. Carapaça, comprimento 1,07, largura 0,89, altura 0,42. Clípeo, altura 0,13. Esterno, comprimento 0,55, largura 0,55. Abdômen, comprimento 1,47, largura 0,87, altura 0,87. Fórmula das pernas 1,2,4,3. Comprimento I/II/III/IV: fêmures $1,40 / 1,33 / 0,97 / 1,30$; patelas $0,25 / 0,25 / 0,22 / 0,22$; tíbias 1,50/1,38/0,86/1,25; metatarsos 1,35/1,13/0,75/1,05; $\operatorname{tarsos} 0,80 / 0,70 / 0,60 / 0,66$. Total 5,30/4,79/3,40/4,48. TmI 0,30. Metatarsos com tricobótrios, exceto o IV. Carapaça (Fig. 1) castanho-avermelhada com bordas mais escuras, área ocular enegrecida, mais larga do que longa. Fila ocular anterior 0,36 e posterior 0,41. Quadrângulo ocular médio, largura anterior 0,12 e posterior 0,20. OMA menores que os demais e OLA, OLP e OMP do mesmo tamanho. Pequenos sulcos na região cefálica, na borda lateral inferior da carapaça, entre as quelíceras e os enditos (Fig. 3). Esterno (Fig. 2) castanho-avermelhado com bordas castanho-escuras, enditos e quelíceras castanhoavermelhadas. Pernas com artículos castanho-amarelados e coxas com detalhes pontilhados castanho-escuros. Abdômen dorsalmente amarelo-claro com laterais e região posterior castanho-escuras. Ventre castanho-escuro, principalmente no entorno das fiandeiras. Palpo com paracímbio em formato de gancho (Fig. 4), divisão embólica translúcida, tégulo inchado e arredondado; êmbolo curvado e pontiagudo distalmente (Fig. 5).

Parátipo $q$ (MCN 40055). Comprimento total 2,47. Carapaça, comprimento 1,10, largura 0,82, altura 0,37. Clípeo, altura 0,11. Esterno, comprimento 0,58, largura 0,56. Abdômen, comprimento 1,62, largura 1,12, altura 1,25. Fórmula das pernas 1,2,4,3. Comprimento I/II/III/IV: fêmures $1,55 / 1,50 / 1,08 / 1,43$; patelas $0,28 / 0,30 / 0,25 / 0,25$; tíbias 1,53/1,33/0,90/1,25; metatarsos 1,30/1,13/0,85/1,05; tarsos $0,86 / 0,80 / 0,58 / 0,72$. Total 5,52/5,06/3,66/4,70. TmI 0,40 . Metatarsos com tricobótrios, exceto na perna IV. Carapaça castanho-avermelhada, mais clara que no macho, com bordas mais escuras, área ocular enegrecida, mais larga do que longa. Fila ocular anterior 0,36 e posterior 0,41 . Quadrângulo ocular médio, largura anterior 0,11 e posterior 0,20. OMA menores que os demais, OLA intermediários, OLP e OMP maiores e do mesmo tamanho. Sulcos na região cefálica, na borda inferior da carapaça. Esterno castanho-avermelhado com bordas castanhoescuras, enditos e quelíceras castanho-avermelhadas. Pernas com artículos castanho-amarelados e coxas com detalhes pontilhados castanho-escuros. Dorso do abdômen amarelo-claro com laterais e região posterior castanho-escuras. Ventre castanho-escuro, principalmente no entorno das fiandeiras. Epígino, internamente, com espermatecas alongadas, esclerotinizadas, ductos com aberturas nas laterais da placa dorsal (Fig. 7).

Variação. Comprimento total: machos 2,08-2,60; fêmeas 2,12-2,68.

Material examinado. BRASIL, Rio Grande do Sul: São Francisco de Paula (CPCN Pró-Mata), 2 ơ, 6 \&, 25.X-23.XI.2000, R. Ott col., pitfall trap (MCN 39416, 39420); 27 o, 39 \&, 25.X.2000-02.II.2001, mesma localidade e coletor (MCTP 18080-18113).

Ecologia. Nas seis áreas amostradas, foram coletados 221 indivíduos com armadilhas de solo entre 25.X.2000 e 18.V.2002; Vesicapalpus serranus sp. nov. foi a sétima espécie de aranha mais abundantemente coletada durante o período, acumulando $3,07 \%$ do total de indivíduos, em um montante de 125 morfoespécies. Foram registrados 221 adultos, dos quais 113 machos e 108 fêmeas. Tomando-se como base cada um dos 60 pontos amostrais, o teste "t pareado" não indicou diferença significativa entre os números registrados para os sexos $(P=0,407)$.

O fenograma obtido no período (Fig. 8) não evidenciou um padrão definido de atividade sazonal para machos ou fêmeas. Foi verificada, todavia, uma redução da atividade desta espécie a partir do final do inverno de 2001 até o início do verão de 2002. A presença de indivíduos adultos, especialmente machos, ao longo de todo ano, sugere um padrão reprodutivo euricrono multivoltino. Diferenças marcantes em fenogramas de espécies de Linyphiidae em anos consecutivos são comuns (Bolduc et al., 2005). No caso desta espécie, o padrão fenológico registrado, com tendência de queda no número de indivíduos capturados a partir da primeira data de coleta, poderia estar relacionado com diferenças bióticas e/ou abióticas entre os anos de estudo ou com um efeito de remoção dos indivíduos e conseqüente

Tabela I. Total de indivíduos de Vesicapalpus serranus sp. nov. coletados em cada armadilha ao longo de todo período amostral (25.X.2000 a 18.V.2002), CPCN Pró-Mata, São Francisco de Paula, RS, Brasil (ARA, Floresta Ombrófila Mista; DP, desvio padrão; EP, erro padrão; PIN, silvicultura de Pinus spp.; SEC, floresta secundária).

\begin{tabular}{lccrrrr}
\hline Transecto/ & ARA1 & ARA2 & SEC1 & SEC2 & PIN1 & PIN2 \\
Armadilha & & & & & & \\
\hline $1 / 1$ & 6 & 2 & 1 & 20 & 2 & 6 \\
$1 / 2$ & 1 & 2 & 7 & 9 & 2 & 2 \\
$1 / 3$ & 4 & 4 & 35 & 21 & 0 & 3 \\
$1 / 4$ & 1 & 2 & 3 & 13 & 1 & 0 \\
$1 / 5$ & 4 & 1 & 2 & 8 & 1 & 1 \\
$2 / 1$ & 0 & 1 & 0 & 0 & 11 & 1 \\
$2 / 2$ & 0 & 5 & 2 & 0 & 1 & 0 \\
$2 / 3$ & 0 & 4 & 2 & 0 & 7 & 0 \\
$2 / 4$ & 1 & 2 & 1 & 1 & 4 & 0 \\
$2 / 5$ & 0 & 0 & 4 & 5 & 3 & 2 \\
\hline Total & 17 & 23 & 57 & 77 & 32 & 15 \\
Média & 1,7 & 2,3 & 5,7 & 7,7 & 3,2 & 1,5 \\
DP & 2,2 & 1,6 & 10,5 & 8,1 & 3,4 & 1,9 \\
EP & 0,7 & 0,5 & 3,3 & 2,6 & 1,1 & 0,6 \\
\hline
\end{tabular}



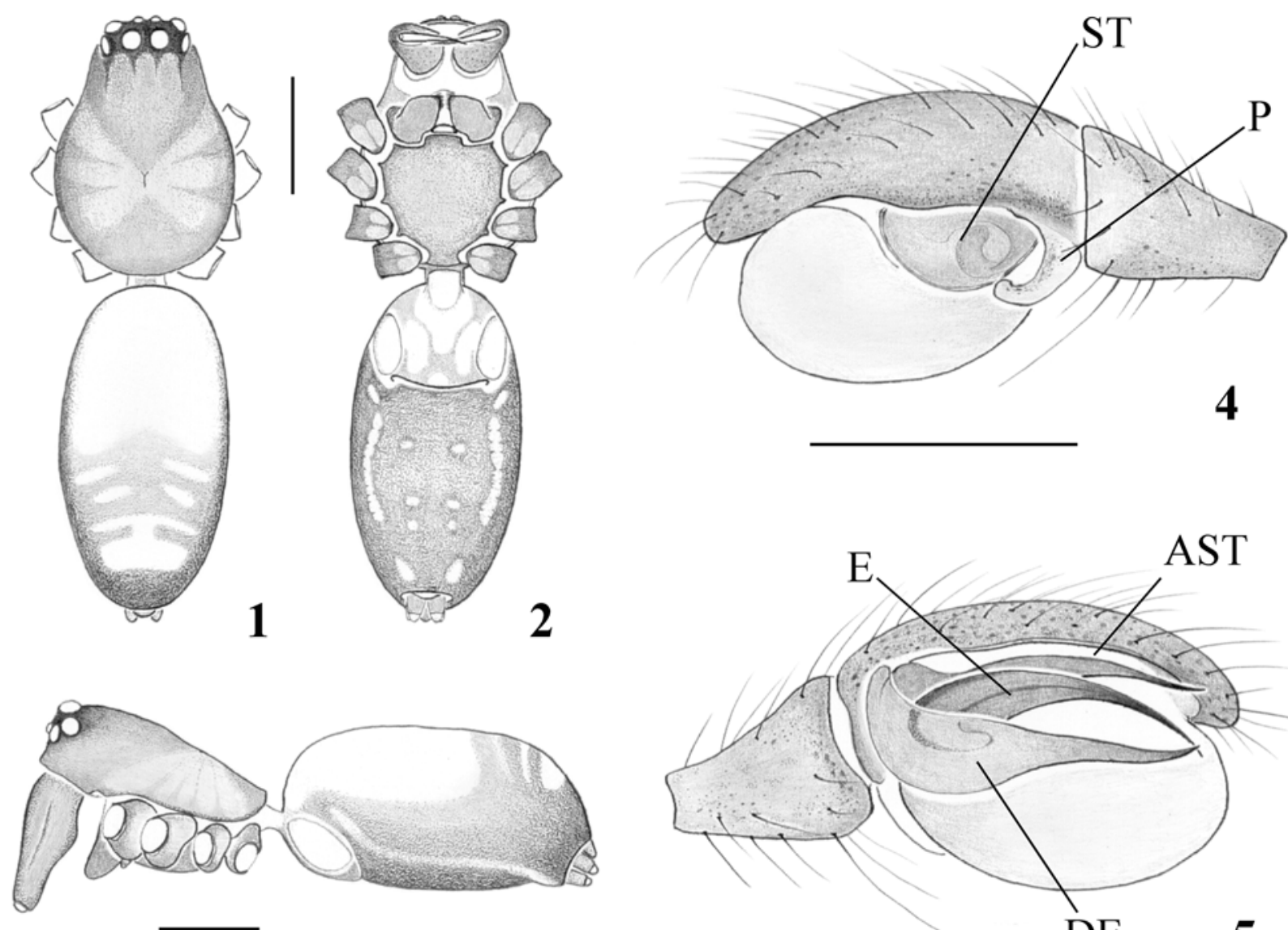

3
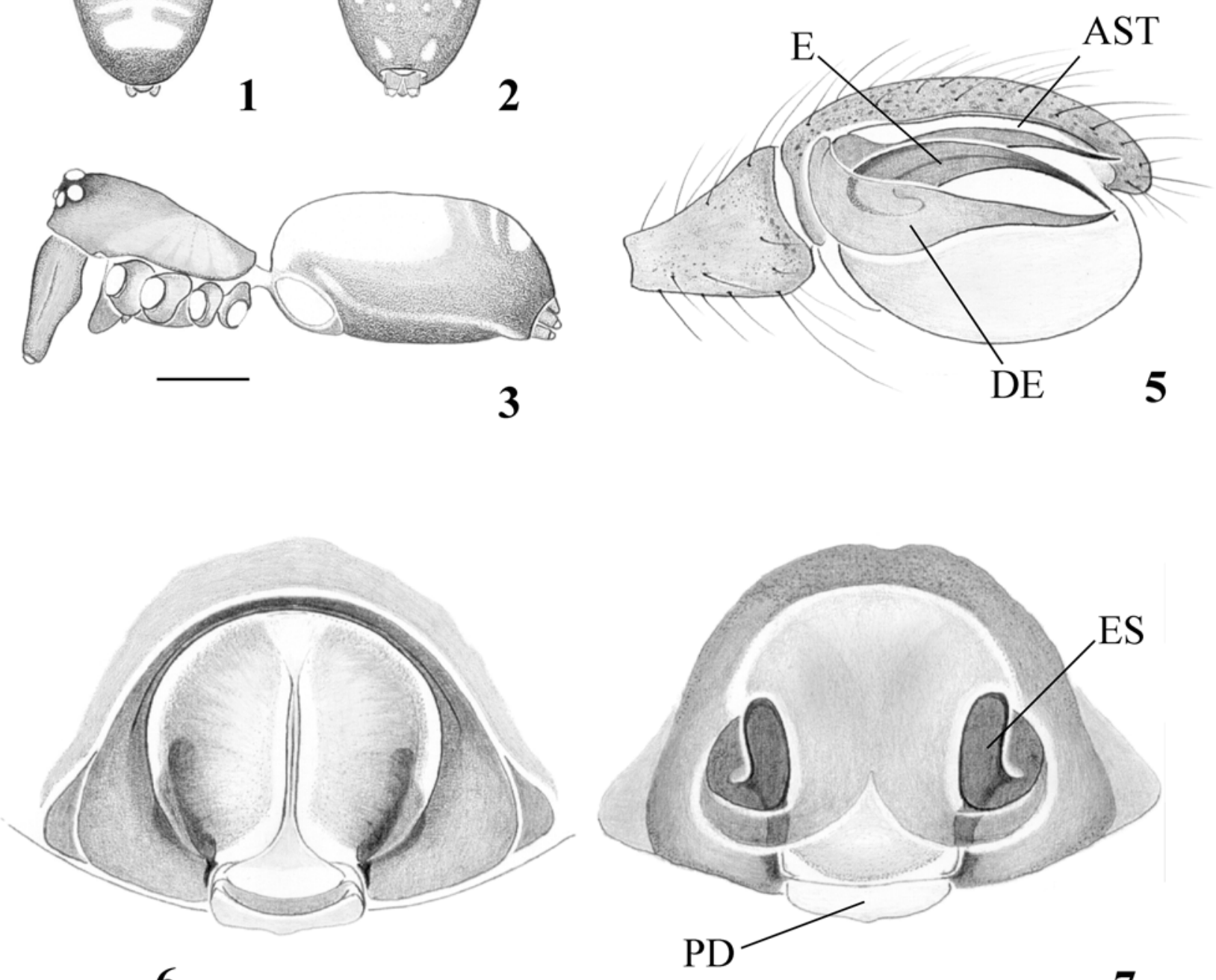

6

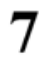

Figs. 1-7. Vesicapalpus serranus sp. nov. 1-5, macho: 1, dorsal; 2, ventral; 3, lateral; palpo: 4, ectal; 5, mesal; 6-7, fêmea, epígino: 6, ventral; 7, dorsal, clarificado (AST, apófise suprategular; DE, divisão embólica; E, êmbolo; ES, espermateca; P, paracímbio; PD, placa dorsal; ST, subtégulo). Barras: figs. 1-3, 0,5 mm; figs. 4-7, 0,2 mm. 
diminuição populacional. Este efeito pode eventualmente ser causado pelo uso deste tipo de armadilha de queda durante períodos mais longos.

A espécie foi claramente mais abundante em ambas as áreas secundárias (Tab. I). Embora diferenças nas abundâncias de espécies de Linyphiidae entre hábitats distintos tenham sido amplamente evidenciadas (DRANEY, 1997), os erros padrões registrados para os conjuntos de amostras obtidas nas áreas secundárias estudadas (Fig. 9) indicam que os resultados devem ser avaliados com cautela. O padrão apresentado pode representar uma possível preferência desta espécie por áreas secundárias. A análise de variância também apresentou diferenças significativas para os valores médios encontrados nos diferentes hábitats florestais $\left(\mathrm{F}_{2,5}=11,348 ; P=0,040\right)$, com o teste de Tukey indicando uma diferença significativa apenas entre áreas primárias e secundárias; todavia, o baixo poder de resposta da análise de variância utilizada ("power" $=0,643<0,800$ ) reforça a possibilidade da diferença numérica observada entre os hábitats ser casual.

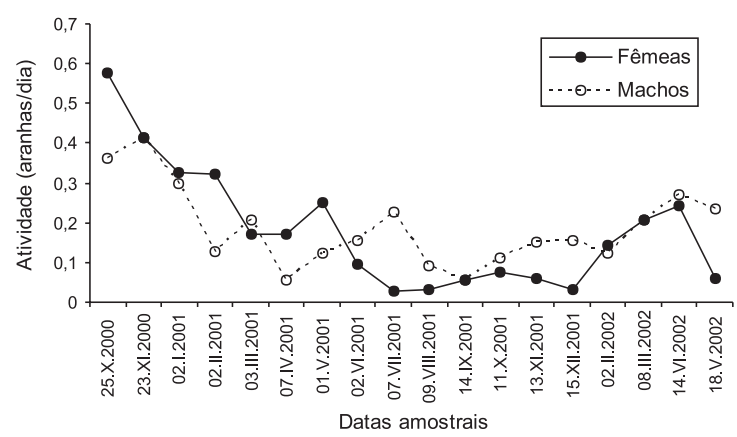

Fig. 8. Fenograma representando a atividade (total de aranhas capturadas/dias de amostragem) de machos e fêmeas de Vesicapalpus serranus sp. nov. em cada data amostral, no período de 25.X.2000 a 18.V.2002, CPCN Pró-Mata, São Francisco de Paula, RS, Brasil.

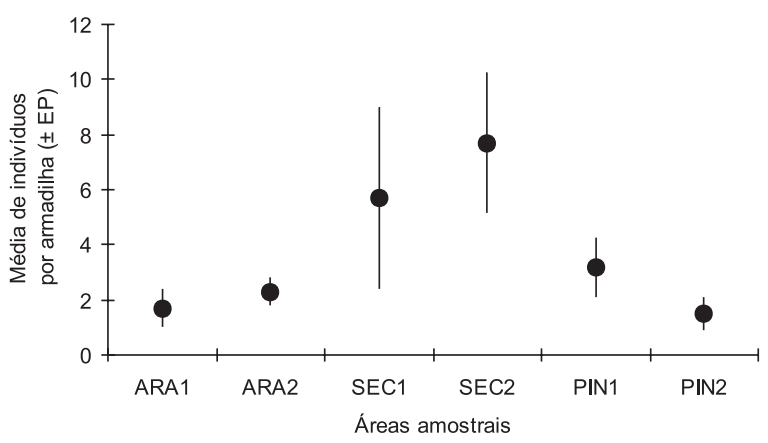

Fig 9. Médias \pm EP de indivíduos de Vesicapalpus serranus sp. nov. capturados por armadilha nas áreas amostrais, no período de 25.X.2000 a 18.V.2002, CPCN Pró-Mata, São Francisco de Paula, RS, Brasil (ARA, Floresta Ombrófila Mista; PIN, silvicultura de Pinus spp.; SEC, floresta secundária).

\section{Vesicapalpus simplex Millidge, 1991 \\ (Figs. 10-16)}

Vesicapalpus simplex Millidge, 1991:56, figs. 182, 183 (holótipo హ', Tobunas, Misiones, Argentina, VII-VIII.1959, O de'Ferrarris col., não-examinado, no AMNH).

Diagnose. O palpo do macho de Vesicapalpus simplex Millidge, 1991 (Millidge, 1991, figs. 182,183) caracteriza-se pela divisão embólica translúcida com uma ponta curvada distalmente (Fig. 16), porção proximal do êmbolo afilada e região distal alongada, ultrapassando a porção distal da divisão embólica, e apófise suprategular robusta anteriormente. Fêmea com epígino semelhante ao de $V$. serranus sp. nov. por apresentar os ductos de fertilização com abertura na base da placa dorsal (Fig. 14); difere pelo átrio formado por uma grande abertura subtriangular com bordas sinuosas (Fig. 13) e espermatecas transversais acima do átrio.

Descrição. O macho foi descrito por MiLlidge (1991), aqui suplementado por ilustrações do palpo em vista ectal e mesal (Figs. 15, 16). Comprimento total 2,77. Carapaça, comprimento 1,07, largura 0,80, altura 0,50. Clípeo, altura 0,22. Esterno, comprimento 0,52, largura 0,52. Abdômen, comprimento 1,55, largura 0,75, altura 0,77. Pernas 1,2,4,3. Comprimento I/II/III/IV: fêmures 1,52/1,37/ $1,00 / 1,40$; patelas $0,27 / 0,27 / 0,25 / 0,25$; tíbias $1,55 / 1,40 / 0,97 /$ 1,35; metatarsos 1,37/1,20/0,89/1,17; tarsos 0,77/0,72/0,57/ 0,72. Total 5,48/4,96/3,68/4,89. TmI 0,30. Metatarsos com tricobótrios, exceto o IV. Carapaça castanho-avermelhada, borda castanho-escura; área ocular escurecida, mais larga $(0,77)$ do que longa $(0,20)$. Quadrângulo ocular médio, largura anterior 0,25, largura posterior 0,42. OMA menores que os demais, OLA intermediários, OMP e OLP maiores e do mesmo tamanho. Esterno castanho-escuro, com tonalidade mais escura que a carapaça. Quelíceras e enditos castanho-avermelhados. Pernas castanhoamareladas. Abdômen dorsalmente amarelo-claro, região posterior com manchas castanho-escuras; ventre castanho-amarelado. Palpo com paracímbio em forma de gancho, tégulo bem desenvolvido e tíbia alongada (Fig. 15).

Fêmea (MCN 40547). Comprimento total 2,27. Carapaça, comprimento 0,95, largura 0,75, altura 0,30. Clípeo, altura 0,30. Esterno, comprimento 0,52, largura 0,52. Abdômen, comprimento 1,25, largura 0,85, altura 0,87. Pernas 1,2,4,3. Comprimento I/II/III/IV: fêmures 1,42/1,35/ 1,05/1,37; patelas 0,27/0,27/0,25/0,25; tíbias 1,40/1,30/0,87/ 1,25; metatarsos 1,25/1,12/0,80/1,10; tarsos 0,77/0,72/0,60/ 0,72. Total 5,11/4,76/3,57/4,69. TmI 0,30. Metatarsos com tricobótrios, exceto na perna IV. Carapaça (Figs. 10, 12) castanha, borda castanho-escura; área ocular enegrecida, mais larga $(0,65)$ do que longa $(0,19)$. Quadrângulo ocular médio, largura anterior 0,15 , largura posterior 0,37 . OMA menores que os demais, OLA e OMP intermediários e OLP os maiores. Esterno castanho-escuro com bordas escurecidas (Fig. 11). Quelíceras e enditos castanhoamarelados. Pernas castanho-amareladas. Abdômen dorsalmente castanho, região posterior castanho-escura; ventre castanho-escuro. Epígino com espermatecas esclerotinizadas e ductos sinuosos (Fig. 14). 


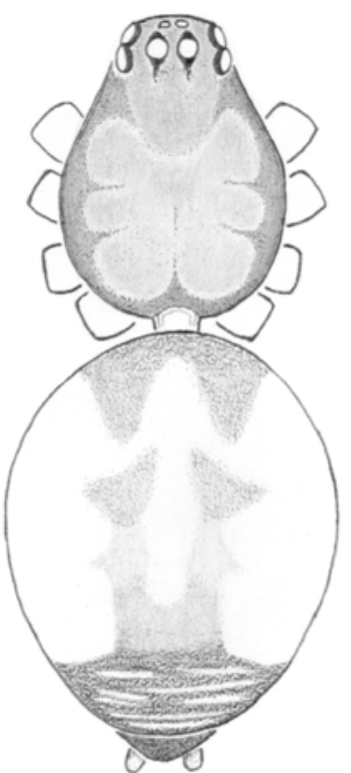

10

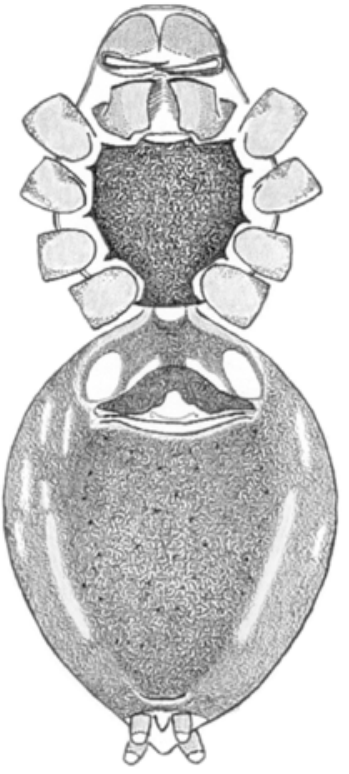

11

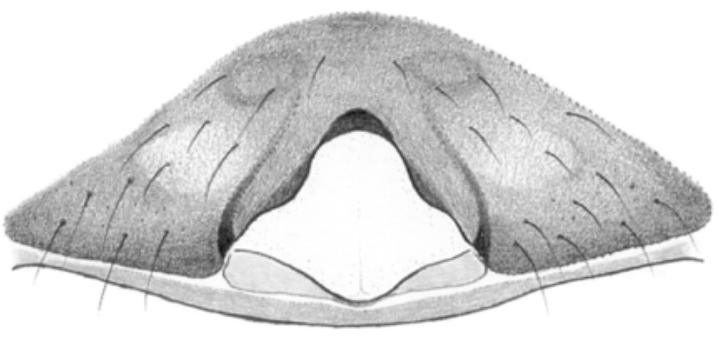

13

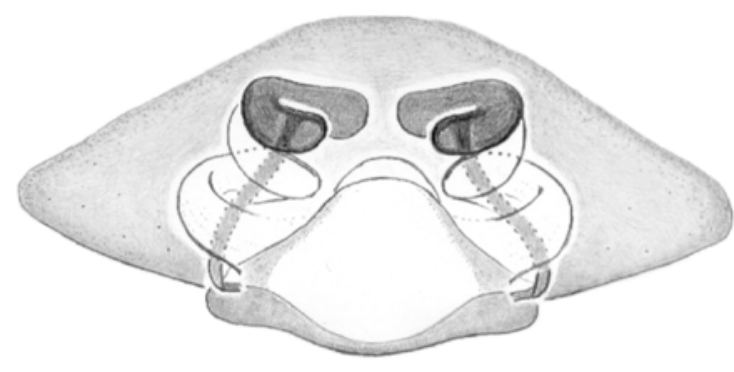

14

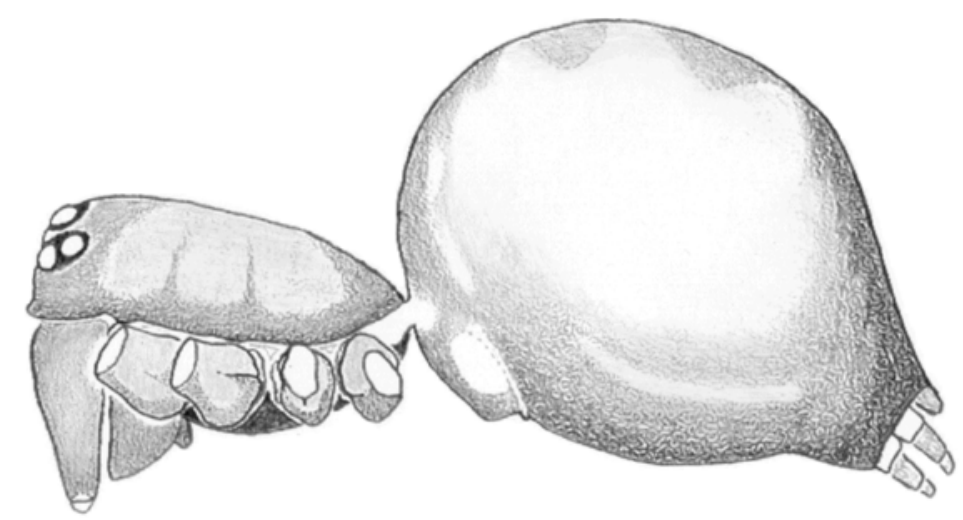

12
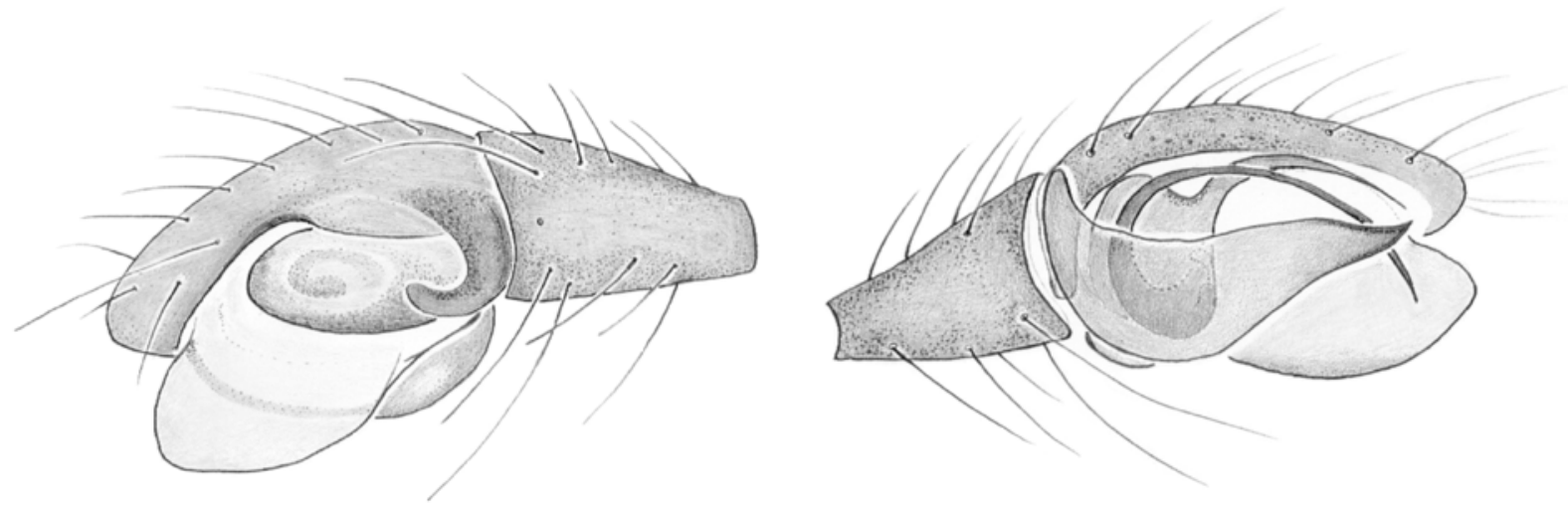

15

16

Figs. 10-16. Vesicapalpus simplex Millidge, 1991. 10-14, fêmea: 10, dorsal; 11, ventral; 12, lateral; 13-14, epígino: 13, ventral; 14, dorsal, clarificado; 15-16, palpo do macho: 15, ectal; 16, mesal. Barras: figs. 10-12, 0,5 mm; figs. 13-16, 0,2 mm. 
Novos registros. BRASIL, Rio Grande do Sul: Santa Cruz do Sul (Aterro do Parque Ambiental da Souza Cruz), 3 ơ, 10.II-28.II, 19.X.2005, S. Oliveira col., pitfall trap (MCN 4054440547); Triunfo, 3 హ, \&, 06.II-11.XII.2002, R. Ott col. (MCN 34442, 34891, 35020).

Distribuição. Brasil (Rio Grande do Sul) e Argentina (Misiones).

Agradecimentos. Aos curadores, pelo empréstimo do material. À Maria Aparecida de L. Marques, pelas sugestões apresentadas. Ao Samuel Oliveira e Andreas Köhler (UNISC), pela disponibilização do material coletado.

\section{REFERÊNCIAS BIBLIOGRÁFICAS}

Bolduc, E.; Buddle, C. M.; Bostanian, N. J. \& Vincent, C. 2005 Ground-welling spider fauna (Araneae) of two vineyards in
Southern Quebec. Community and Ecosystem Ecology 34(3):635-645.

Draney, M. L. 1997. Ground-layer spiders (Araneae) of a Georgia Piedmont floodplain agroecosystem: species list, phenology and habitat selection. The Journal of Arachnology 25:333-351.

Hormiga, G. 1999. Cephalothoracic sulci in Linyphiinae spiders (Araneae, Linyphiidae, Linyphiinae). The Journal of Arachnology 27:94-102.

JANDEL. 1995. SigmaStat statistical user's manual, versions 2.0. San Rafael, Jandel.

Millidge, A. F. 1980. The erigonine spiders of North America. Part 1. Introduction and taxonomic background (Araneae: Linyphiidae). The Journal of Arachnology 8:97-107. 1985. Some linyphiid spiders from South America (Araneae, Linyphiidae). American Museum Novitates 2836:1-78. 1991. Further linyphiid spiders (Araneae) from South America. Bulletin of the American Museum of Natural History 205:1-199.

ZAR, J. H. 1999. Biostatistical analysis. 4ed. New Jersey, Prentice-Hall. 663p

Recebido em março de 2006. Aceito em julho de 2006. ISSN 0073-4721

Artigo disponível em: www.scielo.br/isz 